International Journal of Child, Youth and Family Studies (2016) 7(2): 257-274

DOI: $10.18357 /$ ijcyfs 72201615721

\title{
TEACHERS' EXPERIENCES OF RE-ENGAGING DISENFRANCHISED YOUNG PEOPLE IN LEARNING THROUGH INQUIRY-BASED PEDAGOGIES: A PHENOMENOGRAPHIC STUDY
}

\author{
Debra Talbot and Debra Hayes
}

\begin{abstract}
The potential of inquiry-based pedagogies to improve the learning outcomes of students has gained some support in the literature. In Australia, a small group of schools has adopted inquiry-based pedagogies that foreground students' interests in order to reengage young people who have been disenfranchised from schooling, and also to provide an alternative education for those seeking a more responsive form of educational provision. This paper reports on a phenomenographic analysis of the experiences of teachers in these schools, which was part of a larger study that included interviews with students and their parents or caregivers, classroom observations, and documentary analysis. In developing their curriculum, participating schools drew inspiration from a U.S. organization, Big Picture Learning; hence, a core element involved students learning through their interests (LTI), a feature of Big Picture schooling. The building of inquiry skills, for both students and teachers, is foundational to the success of LTI. This paper aims to contribute to more responsive education provision for disenfranchised young people by documenting the range of variation in teachers' experiences when implementing such a curriculum. We also consider the implications for sustainability of this approach in terms of the intellectual, physical, and emotional demands made on teachers.
\end{abstract}

Keywords: inquiry learning, interest-based learning, phenomenography

Debra Talbot, PhD (corresponding author) is a Lecturer in the Faculty of Education and Social Work at the University of Sydney, Sydney, Australia. Email: debra.talbot@sydney.edu.au

Debra Hayes, PhD is an Associate Professor in the Faculty of Education and Social Work at the University of Sydney, Sydney, Australia. Email: deb.hayes@sydney.edu.au 
International Journal of Child, Youth and Family Studies (2016) 7(2): 257-274

DOI: $10.18357 /$ ijcyfs 72201615721

For some young people, schooling practices have disenfranchising effects that contribute to their disengagement and exclusion from schooling. Alternative education for these young people seeks to change the provision of schooling so that it better meets their needs. This may involve the creation of more caring and flexible relationships between teachers and students. A small number of schools across Australia are also attempting to change the relationship between students, teachers, and knowledge by introducing "learning through interest” (LTI). LTI addresses much of what Smyth, McInerney, and Fish (2013) have identified as being crucial to re-engaging young learners. It places the focus of what needs to be taught squarely on what the young person wants to learn. Designing the curriculum around the young person's interests is dependent on moving beyond a deficit view of young people's interests and capacities. Simultaneously building what McGregor (2011) terms more “egalitarian” relationships between the teacher and student, whereby the teacher acknowledges the sociomaterial dimensions of the young person as increasingly connected and "positioned to question notions of truth and determine their own values outside the school” (p. 2). Through the building of new relationships to knowledge, as constructed through inquiry, alongside supportive interpersonal relationships, the teacher is more able to provide opportunities for students to exercise agency in regard to curricula and pedagogical choices.

We draw on a three-year research project designed to investigate the variation in experiences of students, teachers, and parents/caregivers in six Big Picture-inspired schools in Australia (Hayes, Down, Talbot, \& Choules, 2013). In this paper, we focus on the experiences of the teachers in this larger study, in particular their efforts to implement LTI in an alternative setting. Two important aspects of this LTI program were the internship and the advisory group. The internship provides opportunities for students to spend time working beyond the school setting with a mentor on a topic aligned to their interests. The advisory groups are composed of approximately fifteen students working for extended periods of time with one teacher, known as an advisor, who supports the development of the students' individual and collective interests. The advisory process is highly dialogic; it requires the teacher and students to collaborate and critically interrogate topics of interest. Learning through interest requires well-developed inquiry skills on the part of both teachers and students.

Teachers in our study demonstrated varying degrees of familiarity with terms pertaining to pedagogies of inquiry, such as negotiated curriculum, dialogic pedagogy, and inquiry-based learning. Even so, these terms match well with the teachers' descriptions of their activities, and with what we observed during our site visits. Although much of the substantial research literature on pedagogies of inquiry focuses mainly on the teaching of science and mathematics, this literature provides useful insights into the challenges reported by teachers implementing LTI in any subject. 
International Journal of Child, Youth and Family Studies (2016) 7(2): 257-274

DOI: $10.18357 /$ ijcyfs 72201615721

In the next section, we trace how inquiry pedagogies are situated historically and theoretically, and give examples of how they have been adopted in other times and contexts. The subsequent methodology includes an explanation for the adoption of a phenomenographic approach in this study, and its application in eliciting variations in teachers' experiences when implementing LTI. These experiences are then discussed within four categories: issues with LTI; curriculum modifications to LTI; pedagogies of performance; and what it is like to be a teacher in an LTI classroom. In the conclusion we examine the broader implications, particularly for teachers, of sustaining LTI, and making it more widely available as an alternative approach to learning, particularly for young people who have been disenfranchised from conventional forms of schooling.

\section{Curriculum Design, Interest and Inquiry}

Thinking about curriculum design over the past half century, it could be argued that Greene’s (1971) description of curriculum from the learner's point of view as merely an arrangement of subjects still rings true. Rarely, she says, does curriculum signify a possibility for the learner to be acknowledged as an "existing person, making sense of his own life world" (p. 253). This may be due to our failure to operationalise the aspirations contained in formal curriculum documents (Stenhouse, 1975) but the constraining influence of the ideology underpinning the institutionalised expression of the curriculum is also significant. For teachers, possibly the most constraining of these ideologies is described by Schiro (2008) as the scholar academic ideology which sees the function of education as primarily the induction of students into the various disciplines as they are defined by universities. American educators, such as Sizer (1996), sought to change the way school is "done" and the ways in which curriculum is planned and enacted. Sizer's ideas were taken up and further developed by Elliot Washor and Dennis Littky in their 1995 formulation of the non-profit, non-governmental organization Big Picture Learning which is based on three principles: "first, that learning must be based on the interests and goals of each student; second, that a student's curriculum must be relevant to people and places that exist in the real world; and finally, that a student's abilities must be authentically measured by the quality of her or his work” (Big Picture Learning, 2016). Such formulations of curriculum based on student interest however, present teachers with a number of dilemmas, including, but not limited to: how they prioritise the content of the formal curriculum; how they differentiate the curriculum to meet the needs of different learners; how they assess student learning; and how they select and enact suitable pedagogical practices that support learning through students’ interests (Talbot \& Mockler, 2013).

A pedagogical practice based on inquiry is centered on the learner's questions as the means through which knowledge is identified, constructed, and connected to the learner and their context. Such an approach holds promise for the enactment of a co-constructed, interest-based curriculum. Children begin their lives as inquiry learners, questioning their world and testing their knowledge in both familiar and unfamiliar contexts. It is often the case that formal 
International Journal of Child, Youth and Family Studies (2016) 7(2): 257-274

DOI: $10.18357 /$ ijcyfs 72201615721

schooling fails to enhance their inquiry learning capabilities and only when they leave school do they pick up inquiry for learning again (Washor \& Mojkowski, 2013). For both teachers and their students, inquiry learning begins in engagement with a matter of interest that stimulates the asking of questions. Whether or not interest and hence engagement is maintained may depend on the scope for deeper and ongoing inquiry afforded by the matter of interest. Teacher facilitation of the inquiry process is also critical to ongoing student engagement.

While it may be argued that inquiry pedagogy pre-dates Socrates, it has certainly been a topic of intense research interest since the early 1970s. The systematic and effective training of teachers in inquiry pedagogy became a focus for teacher educators' inquiries; investigations focused on what inquiry teaching looked like and whether all teachers were capable of inquiry teaching; and the effects of inquiry teaching on student learning were examined (Hurst, 1974; Merwin, 1976; Smith \& VanSickle, 1975; Wendel, 1973). Much of the research related to inquiry as pedagogy comes from the subject areas of science and mathematics teaching following the release in the USA of the National Science Education Standards (National Research Council, 1996, 2001). Bybee (1993, 1997) has been writing about reforming science education and teaching for scientific literacy since the early 1990s. Bybee et al. (2006) proposed the 5Es model as a means of scaffolding the inquiry process for both teachers and students. Significantly for an LTI approach, the first " $E$ " in this scaffold represents "engagement" and draws attention to the need to hook learners into a problem or concept that not only has relevance for them but also sufficient depth that it will generate rich questions around which the inquiry can be built. In the 5Es approach this "hook" is usually provided by the teacher, whereas in the interest-based approach we report on here it was the students who initiated engagement in the topic of interest.

In the last two decades inquiry pedagogy has been investigated as a means for addressing declining student participation rates in science and mathematics, particularly in Australia (Goodrum, Hackling, \& Rennie, 2000; Lyons \& Quinn, 2015). The appeal of inquiry pedagogy for these subjects is that it more closely approximates the way in which scientists actually work. In Australia and New Zealand, inquiry pedagogy has also been encouraged across all subject areas through new mandated curriculum. In New Zealand, inquiry pedagogy is directly called for in the curriculum; in Australia , the explicit emphasis is instead placed on student learning associated with what are known as general capabilities, whose purpose is to build a skill set appropriate for learning and life in the $21^{\text {st }}$ century (Australian Curriculum, Assessment and Reporting Authority, 2011; Cowie et al., 2009).

Whether or not teachers are disposed towards, or appropriately skilled to facilitate, inquiry learning is a complex issue. Research investigating the link between teachers' epistemologies and their enacted classroom practices finds that teachers often hold beliefs about knowledge and learning that might be supportive of inquiry learning while their classroom practice remains predominantly transmissive in style (Gates, 2006; Gess-Newsome, Southerland, 
International Journal of Child, Youth and Family Studies (2016) 7(2): 257-274

DOI: $10.18357 /$ ijcyfs 72201615721

Johnston, \& Woodbury, 2003; Windschitl, 2002). This may be because teachers lack experience with conducting genuine research or inquiry for their own learning and hence experience difficulties when it comes to facilitating such a process for the learning of others (Lee, Hart, Cuevas, \& Enders, 2004; Windschitl, 2002). A further compounding factor may be a lack of deep content and procedural knowledge in the subject or subjects related to the field of inquiry (Bybee \& Loucks-Horsley, 2001).

\section{Methodology}

\section{Research Design}

The six schools in our study were at various stages of implementing LTI. We conducted at least two sites visits in each school, and interviewed a total of 20 advisory teachers. The novelty of this design in the Australian context, and the schools’ link to Big Picture Learning, made them readily identifiable. We adopted an approach to the analysis and reporting of findings designed to afford greater anonymity to the participants, while at the same time identifying variations in experiences demonstrably justified by evidence from the transcripts. The highly personalised nature of the LTI approach presented an additional methodological challenge due to its lack of standardisation and its inherent complexity. It was apparent from the outset that any data collection tools would need to be flexible enough to capture the nuances of differences that might exist between sites, and between participants.

\section{Protecting Anonymity}

The phenomenographic approach to analysis, employed in this study as a means to protect the anonymity of participants, is consistent with an epistemology that views knowledge as constructed through an individuals' experiences in the world (Marton \& Booth, 1997). It offers a "kind of research that aims at description, analysis and understanding of experiences" (Marton, 1981, p. 177) and one that allows the researcher to describe the "variations in the ways an aspect of the world has been experienced by a group of people” (Mann, 2009). The heightened protection for participants is built-in to phenomenographic methods through the reporting of results as a depersonalized outcome space in which individual voices are not easily identified (Marton \& Booth, 1997).

\section{Teacher Participants}

The teacher participants in this study were not recruited directly. They were included as a consequence of their connection as an advisory teacher to the student participants who were explicitly recruited. Interviews were conducted with 26 students ranging from those in their first year of secondary schooling to those in their last year. The age range of the students was approximately 12 to 18 years. We invited each student to share an example of their work that illustrated how they learn in an LTI advisory group. These work samples provided a talking point. We did not request an exemplary work sample but one that might represent a challenge, a 
International Journal of Child, Youth and Family Studies (2016) 7(2): 257-274

DOI: $10.18357 /$ ijcyfs 72201615721

process, a work in progress, or something already completed. Students also provided us with a copy of a personal narrative or reflection they had written. After talking with each student, we observed them in their advisory class, and interviewed their advisory teacher. We asked each teacher to elaborate on observations made in their advisory class and matters pertaining to learning that had been raised by their students. We interviewed a total of 20 advisory teachers. In the course of talking about their students' learning and work, teachers also spoke about how that work affected them, even though we did not explicitly question them about these matters. All of the teacher participants in the study had more than five years of teaching experience in a mainstream setting and at least one year of experience with the LTI approach.

\section{Ensuring Trustworthiness}

Interviews were often conducted in the presence of two researchers in order to facilitate debriefing and adoption of a consistent technique for eliciting further detail related to the main questions or to unexpected aspects initiated by the participant. As previously noted, the main questions for teacher interviews had been developed from what each of their students had said about their experiences with LTI. After numerous readings, the interview transcripts were uploaded to a software tool (NVivo) that facilitated the selection and classification of quotations into categories of description, and also the cross-checking and subsequent modification process that occurred between two coders that is essential for inter-coder reliability. Content-related credibility of the analysis was achieved through the researchers' comprehensive understanding of the topic of inquiry, while simultaneously preserving an open understanding of the topic by carefully bracketing and examining their own assumptions in order that the categories of description genuinely arose from the data rather than the researcher's preconceived ideas.

This study is not predicated on claims of generalisability as commonly understood. since the aim is to examine the variations in experiences of the participant group of teachers rather than represent the experiences that might be considered general to the population of teachers as a whole. Collier-Reed, Ingerman, \& Berglun (2009) acknowledge the difficulties for phenomenographic research in establishing what they call "the external horizon of trustworthiness" (p. 351) even when the internal trustworthiness of the study is assured. Chief amongst these is the perception by a wider audience that the categories of description represent something that is not quite real. This issue was addressed by selecting words used by the participant(s) to form the categories of description wherever possible. The strengths of phenomenography for this study were: (a) the capacity to identify variations in experiences of being an LTI teacher through a rigorous and defensible process of analysis of what participants chose to say about those experiences; and, (b) to simultaneously protect the identities of the participants. 
International Journal of Child, Youth and Family Studies (2016) 7(2): 257-274

DOI: $10.18357 /$ ijcyfs 72201615721

To focus our data mining of the full study for the purposes of this paper we chose to address the following questions, from a teacher's perspective:

- What difficulties do teachers face in relation to curriculum design and pedagogy when implementing an LTI approach?

- What are the implications for sustainability of an LTI approach with regard to the demands made on teachers?

The findings below describe and discuss the categories of description related to each of these questions.

\section{Difficulties Experienced by Teachers when Implementing an LTI Approach}

The students enrolled in LTI were described by their teachers as having a range of characteristics that impinged on their interest and engagement with learning in conventional school settings. But most distressing for some teachers was that students were coming into the LTI approach no longer seeing themselves as learners. In speaking about a particular student, one teacher said:

She had become quite disengaged as a learner. Not through behaviour or anything, she just switched off and didn't really see herself as a learner. She talked about - in her speech ... she said I'm going to give [LTI] a go, because it couldn't get any worse.

The LTI approach employed in the study schools is underpinned by the belief that each student has a unique set of interests, needs, and capabilities which influence the design of an individualised learning plan through a collaborative process with their advisor. In talking about their facilitation of LTI it became apparent that teachers were faced with a range of curriculum design and pedagogical issues both during the implementation phase and in the maintenance of the approach. The analysis of what teachers had to say about these issues yielded the following categories of description.

\section{Category 1: Issues with an LTI Approach}

Getting LTI started presented a number of obstacles that teachers attributed to guiding a young person's learning in an area in which they have existing understandings. One teacher outlined issues associated with the initial planning stage in the following way:

If you make too many suggestions about what they should be doing in their project then they say that's not my project any more and they lose interest. We've changed our thoughts about how to manage the projects. When we look at a project we see what could make it richer and deeper but we have to hold off with suggestions and just offer at an appropriate time, "Have you thought about this?" rather than sitting down and planning 
International Journal of Child, Youth and Family Studies (2016) 7(2): 257-274

DOI: $10.18357 /$ ijcyfs72201615721

out from the beginning, on the kids behalf, how they could cover their maths, science etc. So we hold off a bit until the kid is feeling confident and then we make suggestions.

Extending students beyond what they know requires sensitivity on the part of the advisor. This process requires them to have knowledge across the curriculum to connect students with broader bodies of knowledge, and depth of knowledge to facilitate new understandings. If curriculum basics are to be integrated with adequate rigour and depth, teacher judgment in combination with curriculum content knowledge is required, particularly in the initial planning phase of student LTI projects. Teachers also described limited access to specialist facilities such as science laboratories, kitchens, and technical workshops. Supporting the integration of practical learning experiences by booking the use of appropriate facilities sometimes involved timing and sequencing issues.

\section{Category 2: Curriculum Modifications to an LTI Approach}

Local conditions in each school determined the nature and frequency of some of the modifications. The availability of colleagues with subject-based expertise, for example, was an important factor in determining how and when students could receive the facilitation they required for learning about their area of interest. In some settings the spread of expertise across the LTI team of teachers was such that students were given the opportunity to work with teachers other than their advisory teacher in order to access specialist knowledge and skills. In schools where the LTI approach ran alongside mainstream classes, some students were able to attend mainstream classes in order to access specialist teaching and learning experiences, particularly where specialised equipment was required, such as that found in science laboratories, kitchens, and technical workshops.

Compliance with state-based curriculum documents also posed challenges for teachers in terms of ensuring that each student met the requirements for breadth and depth of specified content. Interestingly, for us as researchers who have spent many years observing in classrooms, it seemed that the teachers in an LTI approach often had much higher expectations regarding authentic student engagement with curriculum content than their colleagues in mainstream classrooms where coverage by the teacher often suffices. At the time that this research was conducted, teachers were also beginning to think about how they might design an LTI curriculum in relation to the new Australian Curriculum that would be progressively implemented from 2013 onwards.

We make sure we embed the national curriculum in [the LTI approach], as well as the school requirements, and that's taken us a long time to get that balance of enough of each component to make everyone happy and also to meet their academic outcomes.

Teachers were required to provide evidence and map students’ interest-based learning to subject-based curriculum documents. For Year 11 and 12 students particularly, careful attention 
International Journal of Child, Youth and Family Studies (2016) 7(2): 257-274

DOI: $10.18357 /$ ijcyfs 72201615721

had to be paid to how interest projects meet accreditation requirements. One teacher described this process as “extremely challenging”.

This year all the Yr 11 students are doing [externally assessed] subjects so they have to have a certain amount of points and there are certain things they have to do. I have to keep detailed notes about what they have done around their coursework, of how their interest covers the course work they need to cover.

Finding interest-based internships for each student was a difficult and time consuming process. It was not always possible to find a placement that aligned with the student's interest for a range of reasons including the dependence of certain opportunities on geographical location and work-place safety issues associated with young, untrained people in the work setting. Innovative solutions included the placement of young people with mentors who were likely to provide a positive out-of-school experience and placements designed to build student confidence in the workplace.

In some cases LTI occurred simultaneously with other learning programs designed to meet student's individual needs where gaps in student knowledge, particularly of literacy and inquiry practices, were impediments to pursuing learning interests. Assessment of these needs was made possible through the one-to-one interactions with their advisory teacher:

Spelling was one of those things that she never picked up, and everyone said, "Oh you will pick it up, you will pick it up". She got to this year, and the first piece of writing I got from her, and I said, "Your spelling is atrocious". She said, "I know". Then I worked with [other teachers to help her pick up], for some reason [all the years] in primary school and high school, she hadn’t picked up core spelling skills. We worked on those and we got a sheet of the top 400 words that you need to spell on a regular basis and she worked through that in her own time. We still work on those really hard, core skills, because they can't explore their passions if they don't have those skills.

\section{Category 3: Pedagogy of Performance}

An individualised curriculum to provide for learning through interest has major implications for the way in which teachers assess students' learning. First, each student in an LTI advisory group could potentially be working on a different topic of interest, in a highly individualised way, so traditional forms of "across the class: and "across the grade" assessment are not appropriate. Second, and perhaps more importantly, assessment sends powerful messages to students about the kind of learning that is valued. The major form of assessment for the LTI approach is through exhibition. This requires students to prepare the work they have completed during a term or semester for presentation to an invited discussion group including their parent/caregiver, advisory teacher, and peers. Teachers used a common assessment rubric for oral presentations to facilitate moderation of oral presentations across advisory groups. 
International Journal of Child, Youth and Family Studies (2016) 7(2): 257-274

DOI: $10.18357 /$ ijcyfs 72201615721

Commenting on the affective benefits of exhibitions, one teacher said, "The students respect each other. They realize that: 'even though doing the exhibition is hard for me, all the others have to do it too. I am a part of a community of learners.'”

Journalling and reflection are important tasks that are completed in advisory group time. The journal, as an original product, forms the base of the students' work for exhibition, and teachers use the journalling process to help each student make connections to their learning goals. Students are encouraged to exhibit to their audience not only the various learning "products" they have created but also how these products connect to each other and to their learning goals. The following teacher comments demonstrate how these strategies work to support depth and rigour of student learning:

So their journal is probably their key element. Here's xxx's journal and this is graded too. There's a rubric for the journal as well. The journal's about thinking it's not about writing styles and so the focus isn't on spelling or anything like that, but it's about that deep thinking, which is often difficult to mark, but we have to, to some degree. So, from here they will revisit their journal and they'll take parts from the journal to indicate as evidence.

At [his internship] he made drawings and that will be part of his exhibition. He is looking at legal guidelines for building.

As outlined above in the discussion of curriculum modifications to the LTI approach, sometimes tasks are set in the advisory class in order to ensure that everyone has access to content and skills considered foundational to learning through inquiry. Often, this learning is assessed through a common task that has scope for modification in order that it might still fit within the student's personal interest. These assessment tasks may also be presented at exhibition. Teachers described these tasks in the following ways:

The assessment piece for the last learning plan was this scientific information report, which they could choose but most of the time it was related to whatever they were doing in their learning plan.

The portfolio is actually — and I push this really hard — is a stand-alone document, that any person who walked off the street could pick up and tell me what happened in your year: the highs, the lows, the deep thinking, all of that. That's 100 per cent of their grade for communication for this term. So, it's a significant document.

Assessment through exhibition is not however, without its frustrations. As one teacher describes, it can sometimes be the case that what is exhibited reflects limited skills and incomplete work. The failure of some students to meet certain standards of performance would 
International Journal of Child, Youth and Family Studies (2016) 7(2): 257-274

DOI: $10.18357 /$ ijcyfs 72201615721

be regarded as quite normal in any mainstream assessment regime, but among these teachers it is felt to be not acceptable, and gives rise to reflection on, and questioning of, their pedagogy.

We've had some difficulty in actually getting our hands on concrete products of the work, particularly the harder bits. Sometimes the students are happy to show us their creative stuff, but we really haven't had very much writing, not that we overly value that, but we really haven't seen much finished work from kids. So, it's really difficult for us to get a sense ...

\section{Implications for Sustainability}

The teachers in our study had been supporting students in LTI for two to three years. Some of the issues they faced might be considered "teething” problems, and the teachers also acknowledged that as their experience increased so too did their feelings of success.

\section{Category 4: What is it Like to be a Teacher in an LTI Classroom}

Most teachers regarded working with students in this way as a rewarding experience and said things like:

The projects are now looking more creative and interesting and real.

I'm going home mentally exhausted but fulfilled.

At this early point I haven't gone home and felt I can't be bothered getting up the next day, it isn't worthwhile. It is a good type of tiredness.

It's been a difficult experience - but usually in a good way. What I've most enjoyed is that it is so strong in philosophy, its core tenets. When we talk about it as teachers - we are in big philosophical discussions. As a beginning teacher this is very enriching, all different ideas and approaches.

It is the reaction of the kids that I love, when they get excited about something. One kid is interested in music. She got off the phone and was bouncing off the walls. That is what is the pat on the back for us.

Included within the categories of description for this phenomenon of "being an LTI" teacher, however, are several issues that contribute to threats to the longer-term sustainability of an LTI approach. The first of these threats stems from the way that advisory classes are structured, which provides advisory teachers with very little relief from face-to-face time with their students. This means that, unlike mainstream secondary school teachers, they have almost no opportunities for time within the school day, or indeed beyond it, to prepare or mark student work, to confer with each other, or simply to eat and rest. While most advisory teachers told us 
International Journal of Child, Youth and Family Studies (2016) 7(2): 257-274

DOI: $10.18357 /$ ijcyfs72201615721

that they thought it was important for them to be readily available to their students, many reported, as in categories 2 and 4 above, the emotional and physical demands of being "always on”. Teachers spoke about their physical and emotional exhaustion in the following terms:

I think we got to about the end of term 1 last year and it already felt like the end of term 3. I've never been so tired in my life.... I've never been with a bunch of people that work this hard and I've worked with some really good teams before. We'd be on Facebook to 2 or 3am for those first two terms most nights doing stuff. There's no release time in the school day so we're up late at night making the connections and thinking about our work. I'm not complaining because it's my choice do this but it's really, really tiring and that's one of the low points.

I’ve never been more tired in my life.

It is contact the whole time.

It's bloody hard in here.

For me sitting and being an Advisor but also supporting everybody else is really hard.

For me finding the time to have those one-on-one meetings has been really hard with so many interruptions.

Each of us works a full day, unlike mainstream. It's not just during school hours. Girls, parents, and some mentors call me out of hours.

The second threat resides with the expertise of the teachers themselves and the knowledge, skills, and attitudes required to be a successful LTI teacher. If LTI programs cannot be staffed by the "right" kind of teachers then the approach will not be sustainable. The teachers involved with LTI described that not only was it important to have the right motivation, teachers also had to be able to work effectively as part of a team and, most importantly, be able to work across the curriculum both in terms of content and appropriate pedagogies.

My understanding is that the students drive the learning. My job is to help them identify and map the curriculum. But I'm constantly going back to reassess what I thought [LTI] was about.

I’ve had to re-think my whole teaching practice.

It's all the resources from my previous teaching years that I bring with me because you still need all those tools to teach. It's not just about their interest, it's about skilling them up through their interest and I think there's that balance that's sometimes struggled with. 
International Journal of Child, Youth and Family Studies (2016) 7(2): 257-274

DOI: $10.18357 /$ ijcyfs 72201615721

In [LTI] you have to love teaching and you have to know about 15 to 20 topics at the same time.

It's not black and white limits to subjects - this is maths, this is science. Instead we are finding the connections. That is the idea of it.

I have to be across a broad range of curriculum and for me personally that's my biggest worry. Having the core subject workshops takes the pressure off me a bit to find maths et cetera in kids' interest projects.

In some schools the lack of individual cross-curricula expertise had been overcome by having a team of advisors who shared their varied expertise in order to meet student needs. One teacher explained, “The expertise and the structure of our team is why we feel it's successful. We all have a specialization in an area different to each other.”

In other contexts, limited expertise in certain subject areas has "forced" a reversion to some subjects being taught in more traditional class formations, as one teacher stated, "I have taken on teaching Maths \& English because there is no one else here to do that.”

While cross-curricula integration is common practice in primary school settings it is not the norm in high school where strong divisions along subject-content lines is more usual. Thus, high school teachers have fewer models available to them of cross-curricular designs that have been successfully implemented. This impedes self-directed teacher inquiry for the purposes of professional learning and compounds the difficulties teachers face in responding across the curriculum to a student's learning interest.

\section{Summary of Findings}

Below we present a summary of our findings, by category.

\section{Category 1: Issues with an LTI Approach}

Teachers said they had difficulties with:

1. Finding internships

2. Increasing parental involvement in learning plans and exhibitions

3. Finding ways to address that "kids don't know what they don't know"

4. Ensuring academic rigour and depth

5. The limit to how much guidance students will accept

6. Student and parent perceptions that students are missing curriculum basics

7. Students opting out and playing up

8. Access to practical work facilities 
International Journal of Child, Youth and Family Studies (2016) 7(2): 257-274

DOI: $10.18357 /$ ijcyfs 72201615721

\section{Category 2: Curriculum Modifications to an LTI Approach}

1. Students go to some mainstream classes of their choosing

2. Workshops are offered where the content feeds into interest-based topics

3. Workshops are offered where the content is designed to meet state curriculum

4. Interest-based learning is mapped back to state curriculum outcomes

5. Skills are developed through standard advisory tasks applied to interest-based topic

6. Some forms of mainstream testing or assessment are included

7. Year 11 \& 12 students focus on state curriculum when designing LTI projects

8. LTI runs in conjunction with other learning programs

9. Implementation of a flexible timetable

10. Students co-construct their curriculum with state curriculum in mind

11. Internship is not necessarily linked to interest-based learning

\section{Category 3: Pedagogy of Performance}

1. Original products and presentations for exhibition

2. Tasks set by teachers during advisory or workshops

3. Products reflect a limited range of skills

\section{Category 4: What is it Like to be a Teacher in an LTI Classroom}

1. A need to reflect and question your approach

2. Being more than just a classroom teacher

3. Cross-curriculum content knowledge is essential

4. Having time to pursue learning with each student

5. High physical and emotional demands

6. Having the right skills and motivation is important

7. A rewarding experience

8. Working as a team

9. Working with limited resources

\section{Conclusion}

Like their students, teachers in alternative education often seek opportunities to engage in different kinds of learning relationship. Working outside conventional settings affords them opportunities to support their students in ways that are not generally offered in conventional schooling, which are often less flexible and responsive environments for learning. The teachers in our study were drawing upon prior knowledge and experience to make this transition to LTI. They reported receiving limited specialised professional learning or support to meet the new challenges they experienced. For teachers, the broader implications of making an LTI approach a viable alternative to mainstream schooling fall into three main categories, which relate to (a) 
International Journal of Child, Youth and Family Studies (2016) 7(2): 257-274

DOI: $10.18357 /$ ijcyfs72201615721

teachers' knowledge and professional learning; (b) the physical and emotional demands of being "on" all the time; and (c) difficulties associated with meeting state and national accreditation requirements for students, for both schooling and university entry.

Advisory teachers reported the need to have a well-developed repertoire of pedagogical practices together with a well-equipped understanding in a number of fields of knowledge. Professional learning for teachers implementing LTI might enable them to explore their learning interests beyond their field of specialization, through judicious combinations of external opportunities and contextualized practitioner inquiry.

Teachers acknowledged the demands of the intensely relational dimensions of LTI, which require them to be available to their students all day and even beyond the normal school day without any provision for release from face-to-face time. For sustainability, a design solution must be found that provides teachers with the necessary time for planning, preparation, lunch, and rest without losing the benefits that the high quality of student-teacher relationship brings to student learning.

Teachers in LTI were confronted by the tension of working with student interest while they simultaneously endeavoured to meet syllabus and accreditation requirements. The resolution of such tensions might be achieved through the inclusion of options in the official curriculum that provide scope for collaborative design by students and teachers in order to meet outcomes that reflect broader aspirations for learning rather than specified content. Alternatively, ways might be explored for LTI programs, and the accompanying student portfolios produced for the purposes of assessment in these programs, to be accredited in their own right as part of a direct pathway to tertiary education. The viability and sustainability of alternative education programs for young people are dependent on the professional preparation and support provided to the teachers who facilitate such programs. 
International Journal of Child, Youth and Family Studies (2016) 7(2): 257-274

DOI: 10.18357/ijcyfs72201615721

\section{References}

Anderson, R. (2002). Reforming science teaching: What research says about inquiry. Journal of Science Teacher Education, 13(1), 1-12.

Australian Curriculum, Assessment and Reporting Authority. (2011). General Capabilities in the Australian Curriculum. Retrieved from http://www.australiancurriculum.edu.au/GeneralCapabilities/Overview/Generalcapabilities-in-the-Australian-Curriculum

Big Picture Learning: Our Story. (2016). Retrieved from http://www.bigpicture.org/apps/pages/index.jsp?uREC_ID=389353\&type=d\&pREC_ID=88 2353

Bybee, R. (1993). Reforming science education: Social perspectives and personal reflections. New York, NY: Teachers College Press.

Bybee, R. (1997). Achieving scientific literacy: From purposes to practices. Westport, CT: Heinemann.

Bybee, R., \& Loucks-Horsley, S. (2001). National science education standards as a catalyst for change: The essential role of professional development. In J. Rhoton \& P. Bowers (Eds.), Professional development planning and design (pp. 1-12). Reston, VA: NSTA Press.

Bybee, R., Taylor, J. A., Gardner, A., Van Scotter, P., Carlson, J., Westbrook, A., \& Landes, N. (2006). The BSCS 5E instructional model: Origins and effectiveness. Colorado Springs, CO: BSCS.

Collier-Reed, B., Ingerman, A., \& Berglund, A. (2009). Reflections on trustworthiness in phenomenographic research: Recognising purpose, context and change in the process of research. Education as Change, 13(2), 339-355.

Cowie, B., Hipkins, R., Boyd, S., Bull, A., Keown, P., Mcgee, C., ... Yates, R. (2009). Curriculum implementation exploratory studies: Final Report. Retrieved from Ministry of Education, New Zealand Government Education Counts website: http://www.educationcounts.govt.nz/publications/curriculum/57760/1

Furtak, E., Seidel, T., Iverson, H., \& Briggs, D. (2012). Experimental and quasi-experimental studies of inquiry-based science teaching: A meta-analysis. Review of Educational Research, 82(3), 300-329.

Gates, P. (2006). Going beyond belief systems: Exploring a model for the social influence on mathematics teacher beliefs. Educational Studies in Mathematics, 63(3), 347-369. doi:10.1007/s10649-005-9007-z 
International Journal of Child, Youth and Family Studies (2016) 7(2): 257-274

DOI: $10.18357 /$ ijcyfs 72201615721

Geier, R., Blumenfeld, P., Marx, R., Krajcik, J., Fishman, B., Soloway, E., \& Clay-Chambers, J. (2008). Standardized test outcomes for students engaged in inquiry-based science curricula in the context of urban reform. Journal of Research in Science Teaching, 45(8), 922-939.

Gess-Newsome, J., Southerland, S., Johnston, A., \& Woodbury, S. (2003). Educational reform, personal practice, and dissatisfaction: The anatomy of change in college science teaching. American Educational Research Journal, 40(3), 731-767.

Goodrum, D., Hackling, M., \& Rennie, L. (2000). The status and quality of teaching and learning of science in Australian schools: A research report. Canberra, Australia: Department of Education, Training and Youth Affairs.

Greene, M. (1971). Curriculum and consciousness. Teachers College Record, 73(2), 253-270.

Hayes, D., Down, B., Talbot, D., \& Choules, C. (2013). Big Picture Education Australia: Experiences of students, parents/carers \& teachers. (Research report). Sydney, Australia: Faculty of Education and Social Work, University of Sydney.

Hurst, J. (1974). Competency-based modules and inquiry teaching. The Journal of Experimental Education, 43(2), 35-39.

Johnston, K., \& Hayes, D. (2008). "This is as good as it gets": Classroom lessons and learning in challenging circumstances. Australian Journal of Language and Literacy, 31(2), 109-127.

Lee, O., Hart, J., Cuevas, P., \& Enders, C. (2004). Professional development in inquiry-based science for elementary teachers of diverse students groups. Journal of Research in Science Teaching, 41(10), 1021-1043.

Lingard, B., Hayes, D., \& Mills, M. (2006). Teachers and productive pedagogies: Contextualising, conceptualising, utilising. Pedagogy, Culture \& Society, 11(3), 399-424.

Littky, D., \& Grabelle, S. (2004). The big picture: Education is everyone’s business. Alexandria, VA: Association for Supervision and Curriculum Development.

Lyons, T., \& Quinn, F. (2015). Understanding declining science participation in Australia: A systemic perspective. In E. Henriksen, J. Dillon, \& J. Ryder (Eds.), Understanding student participation and choice in science and technology education. Dordrecht, Netherlands: Springer.

Mann, L. (2009). Research method - Phenomenography: Critical features of phenomenography. Retrieved from http://aaee-scholar.pbworks.com/w/page/1177079/Research\%Method\%20\%20Phenomenography

Marton, F. (1981). Phenomenography - Describing conceptions of the world around us. Instructional Science,10, 177-200. 
International Journal of Child, Youth and Family Studies (2016) 7(2): 257-274

DOI: $10.18357 /$ ijcyfs72201615721

Marton, F., \& Booth, S. (1997). Learning and awareness. Mahwah, NJ: Lawrence Erlbaum Associates.

McDonald, J. P., Klein, E. J., Riordan, M., \& Broun, S. (2003). Scaling up the Big Picture. (Monograph 1, Scaling-Up Study). New York, NY: Steinhardt School of Education, New York University.

McGregor, G. (2011). Engaging Gen Y in schooling: The need for an egalitarian ethos of education. Pedagogy, Culture \& Society, 19(1), 1-20.

Merwin, W. (1976). An inquiry into inquiry teaching. The High School Journal, 59(4), 159-162.

National Research Council. (1996). National science education standards. Washington, DC: National Academies Press.

National Research Council. (2001). Inquiry and the national science education standards. Washington, DC: National Academies Press.

Schiro, M. (2008). Curriculum theory: Conflicting visions and enduring concerns. Thousand Oaks, CA: Sage.

Sizer, T. (1996). Horace's hope: What works for the American high school. New York, NY: Houghton Mifflin Company.

Smith, B., \& VanSickle, R. (1975). Focusing on inquiry teaching behaviours. The High School Journal, 58(7), 285-294.

Smyth, J., McInerney, P., \& Fish, T. (2013). Blurring the boundaries: From relational learning towards a critical pedagogy of engagement for disengaged disadvantaged young people. Pedagogy, Culture \& Society, 21(2), 299-320.

Stenhouse, L. (1975). An introduction to curriculum research and development. London, UK: Heinemann.

Talbot, D., \& Mockler, N. (2013). Australian curriculum classroom approaches: Science. South Yarra, Australia: Palgrave MacMillan.

Washor, E., \& Mojkowski, C. (2013). Leaving to learn: How out-of-school learning increases student engagement and reduces dropout rates. Westport, CT: Heinemann.

Wendel, R. (1973). Inquiry teaching: Dispelling the myths. The Clearing House, 48(1), $24-28$.

Windschitl, M. (2002). Inquiry projects in science teacher education: What can investigative experiences reveal about teacher thinking and eventual classroom practice? Science Teacher Education, 87(1), 112-143. doi:10.1002/sce.10044 